\title{
COMPARISON OF LOW CYCLE (NOTCH) FATIGUE BEHAVIOUR AT TEMPERATURE IN SINGLE CRYSTAL TURBINE BLADE MATERIALS
}

\author{
P.A.S. Reed and M.D. Miller
}

Engineering Materials Research Group, School of Engineering Sciences, University of Southampton, Highfield, Southampton, SO17 1BJ

Keywords: Notch fatigue, CMSX4, porosity, fatigue initiation, lifing model, scatter

\begin{abstract}
The scatter in notch fatigue lifetimes of CMSX 4 at $650^{\circ} \mathrm{C}$ and $725^{\circ} \mathrm{C}$ in air and vacuum and with Rene N5 in air at $650^{\circ} \mathrm{C}$ is compared under the same (plastic) notch strain range levels. Rene N5 shows shorter lifetimes under equivalent conditions and always exhibits multiple initiation sites. The role of interdendritic porosity in initiating fatigue in both alloys is identified, and the number of initiation sites is found to directly affect fatigue life. In air in CMSX4 and Rene N5, subsurface pores initiate fatigue, and this is believed to be due to the repeated in-filling of surface pores by oxidation product, reducing their associated stress concentration and effectively deactivating them as a fatigue initiation site. Tests in vacuum support this hypothesis as cracks do initiate at surface porosity under vacuum conditions. An attempt to evaluate initiating porosity distributions, has indicated a correlation between total area of initiating porosity and fatigue lifetime, which to some extent may allow for crack coalescence behaviour. A deterministic fracture mechanics based model has been proposed to allow for the effect of pore shape, size and position in determining subsequent fatigue life (and hence scatter). The predictions of the model have been assessed using full factorial design of experiments, assessing the effects of variability in pore shape, size and distance below the notch root, as well as the materials parameters (crack growth laws and $K_{\max }$ ) used in the lifing calculation. The model successfully explains some, but not all of the observed scatter in lifetimes.
\end{abstract}

\section{Introduction}

Fatigue initiation may occur at notches in turbine blades (e.g. transition regions between platform and aerofoil or "fir-tree" roots). Turbine blades are often coated, however this protective coating is typically not applied below the platform in the fir-tree region. In addition, while the primary orientation (the effective tensile axis) of a turbine blade produced by directional solidification is nominally in a $<001>$ direction, the secondary (notch) orientation is not usually controlled. This could affect the operation of slip systems at the notch root and hence fatigue behaviour [1]. A comparison of environment and secondary notch orientation effects on fatigue initiation behaviour of uncoated CMSX4 and Rene N5 at appropriate service temperatures under low cycle fatigue conditions has therefore been made. A model based on the mechanistic insights gained by the experimental programme has been devised and the sensitivity of lifetime predictions to the various defect population features and materials performance parameters has been assessed. The effect of input uncertainty (e.g. loading and environment conditions) can then be assessed on the lifetime prediction. A further aim in developing such local physically based lifing models is that they can be used as part of a life cycle costing approach during preliminary design considerations. An ability to assess the effect of uncertainty in model inputs (reflecting stress, temperature and materials variability) is essential in using such models in very early stages of aeroengine design.

CMSX-4 is a second generation Ni-based single crystal superalloy that contains a number of alloying additions such as $\mathrm{W}$, Mo and Co to provide solid solution strengthening as well as Al, Ti and Ta that provide efficient $\gamma^{\prime}$ precipitate strengthening (volume fractions $\sim 70 \%$ ). Another important alloying addition is $3 \%$ Rhenium, which is found predominantly in the $\gamma$ matrix, where it retards coarsening of the $\gamma^{\prime}$ strengthening phase and increases $\gamma / \gamma^{\prime}$ misfit. It has been proposed that Re clusters form within the $\gamma$ matrix channels and act as efficient obstacles to dislocation movement to contribute significantly to the high strength of the alloy [2] although segregation of Re to the $\gamma / \gamma^{\prime}$ interface has also been reported [3]. Creep behaviour of CMSX-4 is well documented between $750^{\circ} \mathrm{C}-1000^{\circ} \mathrm{C}$ where it exhibits excellent creep resistance due to hardening by the $\gamma^{\prime}$ precipitates and often multiple crack initiation is seen from microporosity and inclusions. However the fatigue behaviour of CMSX-4 is less commonly reported. The literature suggests that crack initiation in CMSX-4 appears to be controlled by porosity and/or oxidation depending on the applied temperature and stress levels [4]. Oxidation is also suggested to be a dominant factor in crack growth [5] with oxidation at the crack tip becoming important at higher temperatures and oxide induced closure causing crack tip blunting and reducing crack growth rates [6].

Rene N5 is another second generation single crystal superalloy, comparable in many ways with CMSX4, also containing significant $\mathrm{Re}$ and most literature focuses on its thermal oxidation behaviour as part of a coated turbine blade system. Limited fatigue evaluation [7] has been carried out at high frequency at room temperature, where planar faceted crack growth has been observed along $\{111\}$ planes as well as along $\{100\}$ directions.

\section{Methodology}

U-notched bend specimens with an $<001>$ tensile axis and either a $<100>$ or $<110>$ notch direction (known as orientation A or B respectively) were used. The orientations are shown in Figure 1. The bars were $50 \mathrm{~mm}$ by $8 \mathrm{~mm}$ by $8 \mathrm{~mm}$ containing a notch diameter of $4 \mathrm{~mm}$, polished to $1 \mu \mathrm{m}$ finish, giving a stress concentration of 2 (as shown in Figure 2). Specimens were tested in 3-point bend using an Instron 8501 servo-hydraulic machine fitted with a high temperature and vacuum chamber. Low frequency tests $(0.25 \mathrm{~Hz})$ were conducted at an $\mathrm{R}$ ratio of 0.1 and test temperatures of $650^{\circ} \mathrm{C}$ and $725^{\circ} \mathrm{C}$ using a 1-1-1-1 trapezoidal waveform and a constant load range giving a notch strain range of $1.38 \%$ to give lifetimes between $3,000-30,000$ cycles. 
Temperature was controlled to within $\pm 1^{\circ} \mathrm{C}$ and vacuum levels to $1 \times 10^{-5}$ bar. Field Emmission Gun Scanning Electron microscopy (FEG-SEM) of the fractured surfaces was used to identify crack initiation points and determine fracture modes. Plain polished samples and polished and etched samples were also exposed at $650^{\circ} \mathrm{C}$ for between 1 and 256 hours to study oxidation behaviour.

A

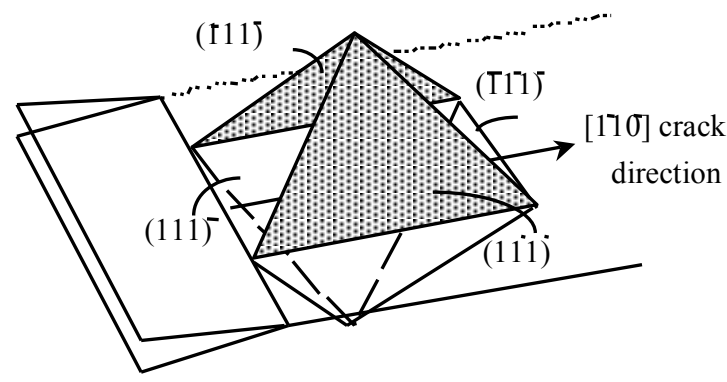

(111)

[010] crack direction

(111)

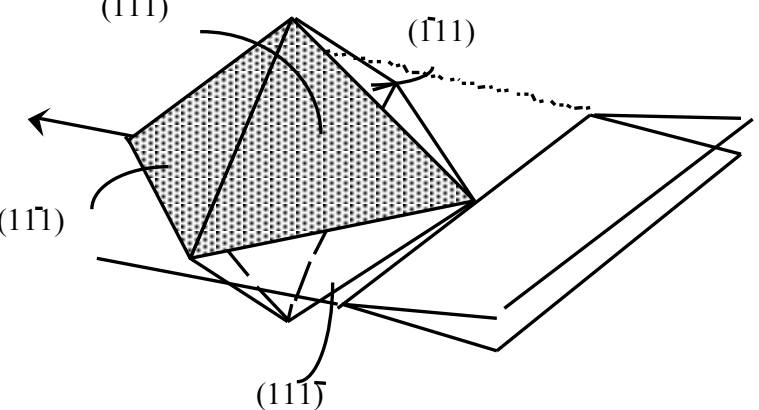

(111)

Figure 1. Notch plane orientations and disposition of $\{111\}$ slip planes about the notch plane for $<100>$ primary oriented single crystal specimens

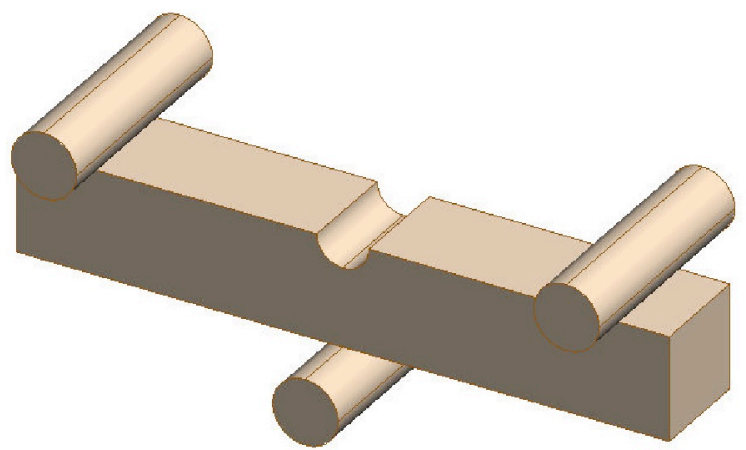

Figure 2. Notch bend bar geometry tested in three point bend

\section{Results}

The $\gamma$ matrix was preferentially oxidised in both CMSX4 and Rene N5 after $1 \mathrm{~h}$ exposure. Post-failure examination in the notch root showed the oxide scale was very thick, with surface cracking and apparent rumpling of the scale observed (Figure 3 ) as well as circular oxide features of the scale of surface porosity that appeared filled with oxide. In Rene N5, preferential oxidation of interdendritic carbides was also observed (Figure 4). A fuller description of the long crack fatigue propagation behaviour in CMSX4 at $650^{\circ} \mathrm{C}$ is given in [8]. In brief however, it was observed that the $\langle 110\rangle$ notch direction (Orientation A) has a generally better fatigue crack propagation (fcp) resistance, particularly at lower $\Delta K$ levels. Faster crack growth rates are also generally seen in vacuum $c f$. air

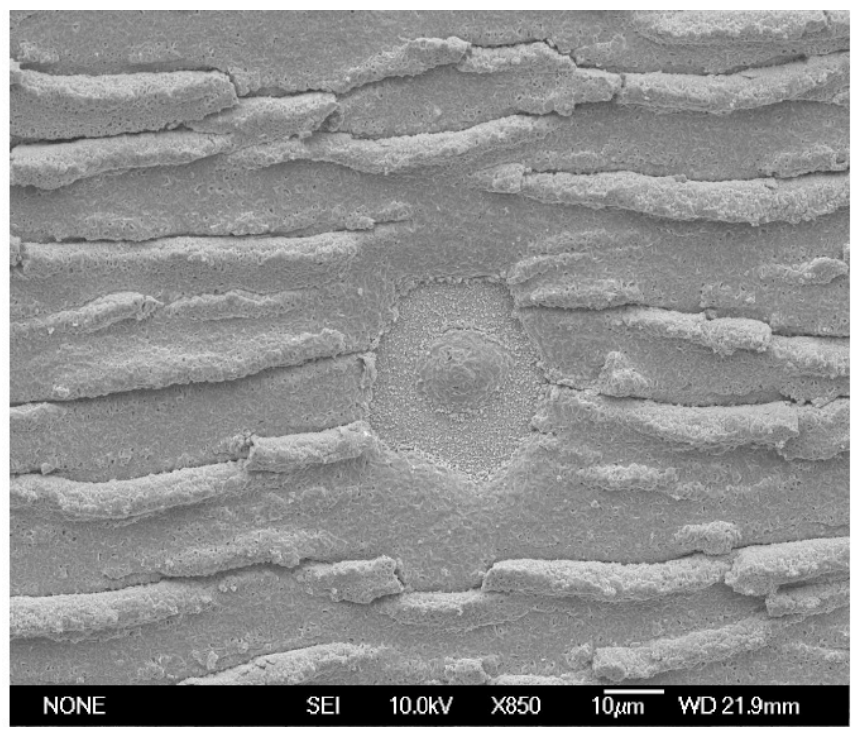

Figure 3. Rumpled oxide scale in notch root of CMSX4 (including circular in-filled surface pore feature)

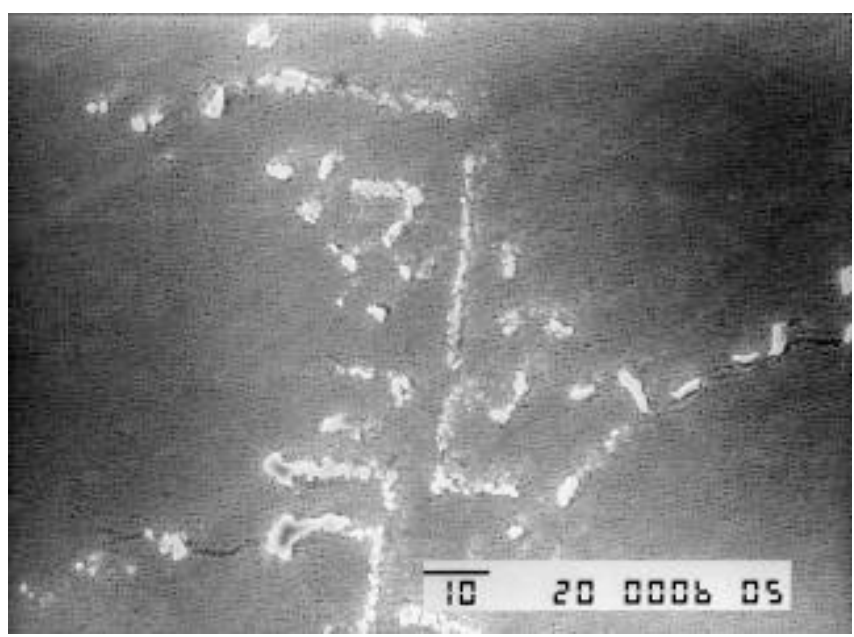

Figure 4. Oxidised interdendritic carbides in Rene N5 samples after exposure at $650^{\circ} \mathrm{C}$ in air for $1 \mathrm{~h}$

Table 1 shows a summary of the U-notch tests completed and their associated lifetimes. Generally tests conducted in vacuum gave longer lifetimes than the equivalent tests in air however there appears to be no clear effect of orientation upon the specimen lifetimes. Previous work [9] in CMSX4 found that roomtemperature fracture surfaces exhibit large facets which correspond to the $\{111\}$ planes, however at $650^{\circ} \mathrm{C}$, fracture surfaces appeared less faceted as shown in Figures 5a and b. A number of major crack initiation points can be identified close to the notch at low magnification. At $725^{\circ} \mathrm{C}$ the fracture surfaces looked similar to those obtained at $650^{\circ} \mathrm{C}$ although the side facets formed were slightly smaller. At both temperatures heavy oxidation obscured the detail of the notch root surface. In comparison, the vacuum tests showed much more faceted fracture surfaces at both $650^{\circ} \mathrm{C}$ and $725^{\circ} \mathrm{C}$. 
Table I. Notch fatigue lifetime data for CMSX4 and Rene N5, all tested at $\Delta \varepsilon=1.38 \%$ in the notch root (where * indicates multiple initiation sites were observed)

\begin{tabular}{|l|l|l|l|}
\hline Temp & Material & Env. (A/B) & Life \\
\hline $650^{\circ} \mathrm{C}$ & CMSX4 & air (A) & 25500 \\
$650^{\circ} \mathrm{C}$ & CMSX4 & air (B) & $6500^{*}$ \\
$650^{\circ} \mathrm{C}$ & CMSX4 & vacuum (A) & $15871^{*}$ \\
$650^{\circ} \mathrm{C}$ & CMSX4 & vacuum (B) & 9378 \\
$725^{\circ} \mathrm{C}$ & CMSX4 & air (A) & $5271^{*}$ \\
$725^{\circ} \mathrm{C}$ & CMSX4 & air (B) & $13717^{*}$ \\
$725^{\circ} \mathrm{C}$ & CMSX4 & vacuum (A) & 11363 \\
$725^{\circ} \mathrm{C}$ & CMSX4 & vacuum (B) & 19841 \\
$650^{\circ} \mathrm{C}$ & Rene N5 & air (A) & $3346^{*}$ \\
$650^{\circ} \mathrm{C}$ & Rene N5 & air (A) & $11490^{*}$ \\
$650^{\circ} \mathrm{C}$ & Rene N5 & air (A) & $4945^{*}$ \\
$650^{\circ} \mathrm{C}$ & Rene N5 & air (B) & $3325^{*}$ \\
$650^{\circ} \mathrm{C}$ & Rene N5 & air (B) & $2573^{*}$ \\
$650^{\circ} \mathrm{C}$ & Rene N5 & air (B) & $3507^{*}$ \\
\hline
\end{tabular}

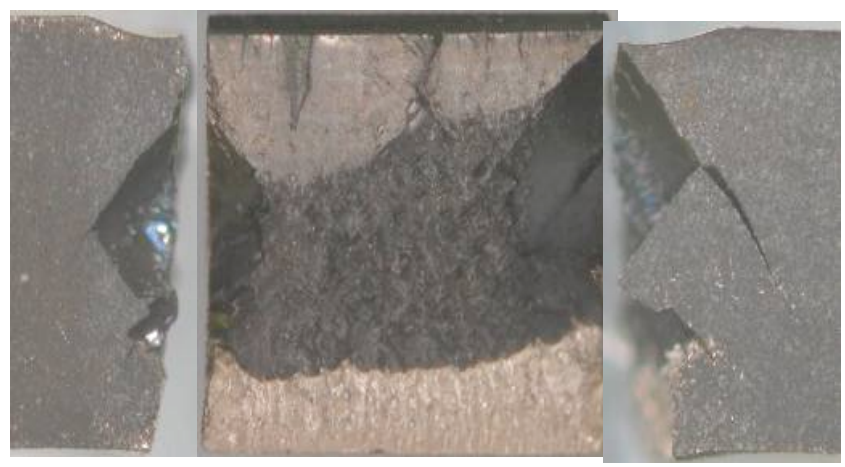

Figure 5(a) overview of CMSX4 $\left(<100>\right.$ notch) $650^{\circ} \mathrm{C}$ in air

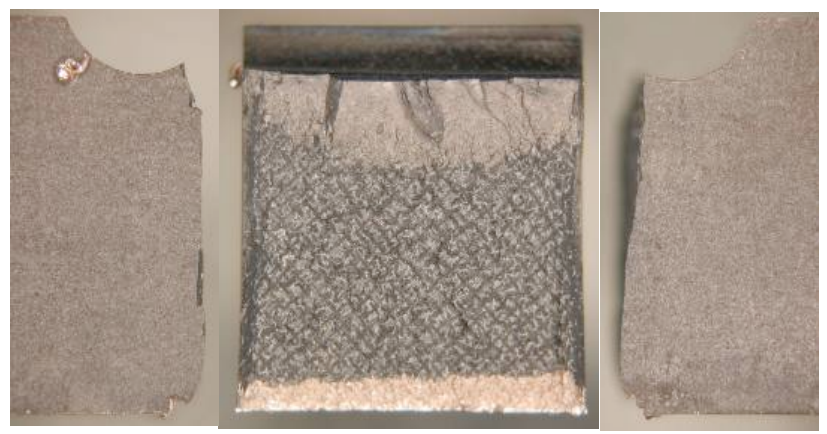

Figure 5(b) overview of Rene N5 $\left(<110>\right.$ notch) $650^{\circ} \mathrm{C}$ in air

Crack initiation in air does not occur from notch root surface features (e.g. surface cracks). The thick oxide layer in the notch root obscures any surface pores, filling them with oxide scale, and increased oxidation appears associated with these surface pores (as shown in Figure 3). All fatigue crack initiation events in the air tests were associated with sub-surface interdendritic pores (as shown in Figure 6) which were characterised by a halo around the pore. In contrast, under vacuum conditions, fatigue crack initiation from surface or close-to-surface pores was typically observed (Figure 7) and clear evidence of planar slip processes at the crack tip were observed from sectioned fracture surfaces of faceted features. In Rene $\mathrm{N} 5$, tested at $650^{\circ} \mathrm{C}$ in air, very similar initiation behaviour was seen but in all cases multiple initiation sites were observed (Figure 5b)

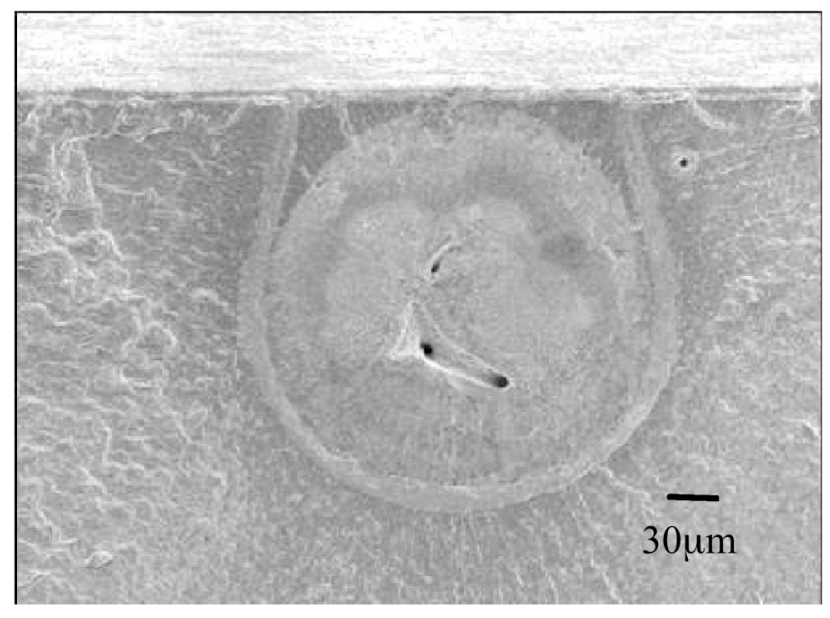

Figure 6. Sub-surface crack initiation from pore surrounded by halo in CMSX4 tested in air at $650^{\circ} \mathrm{C}$

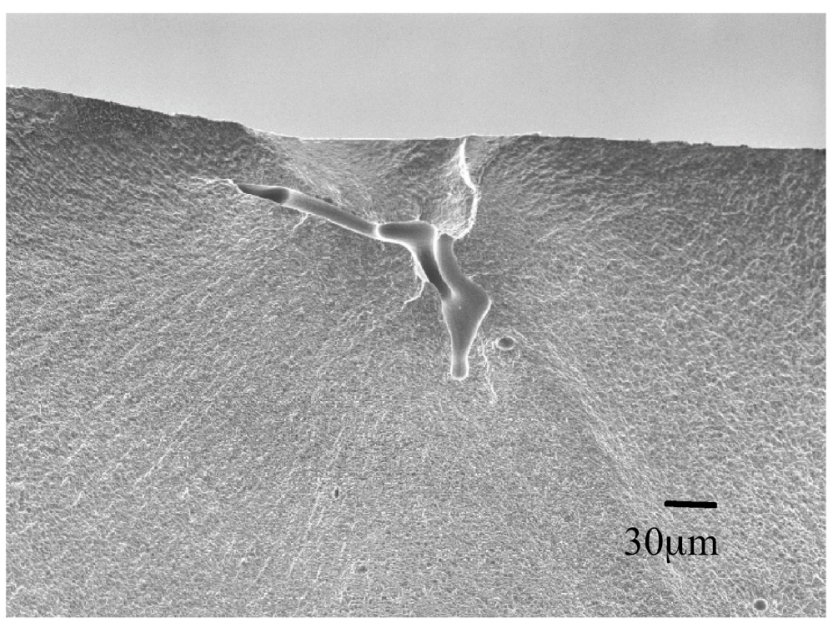

Figure 7. Surface crack initiation from pore in CMSX4 tested in vacuum at $650^{\circ} \mathrm{C}$

Porosity distributions of the initiating pores were then assessed in two different ways. Porosity measurements were in all cases taken from SEM shots of the fracture surfaces, but the typically complex shapes of the porosity (see Figures 6 and 7) made simplified definitions of the pore shapes, sizes and positions in terms of e.g. major and minor axis-lengths, orientation etc non trivial. For each pore a centroid was estimated, and the depth, $d$, below the notch root measured. The greatest distance across the pore tip to tip and passing through the centroid was recorded as the major dimension $(x)$ the minor dimension $(y)$ was measured at $90^{\circ}$ to the major dimension as an average along the pore shape (a necessarily subjective measurement). Tessellation analysis software programme (TAP) developed at Southampton University [10] took an alternative set of porosity measurements by measuring the actual area of the pore from the digital image and calculating an aspect ratio (defined as the maximum chord length divided by the perpendicular width). The TAP measurements showed that the overall initiating porosity level in CMSX4 was $1.3 \%$ (analysed over a $28.79 \mathrm{~mm}^{2}$ area) and in Rene N5 was only $0.29 \%$ (analysed over a $27.42 \mathrm{~mm}^{2}$ area). However the more 
detailed TAP measurements shown in Table II indicate other important differences in the porosity distributions:

Table II. TAP measurements for initiating porosity in CMSX4 (Rene N5 data given in parentheses) NN Dist = nearest neighbour distance, Angle is defined with respect to the crack propagation direction.

\begin{tabular}{|l|l|l|l|l|}
\hline $\begin{array}{l}\text { TAP } \\
\text { measurement }\end{array}$ & $\begin{array}{l}\text { Area } \\
\left(\mu \mathrm{m}^{2}\right)\end{array}$ & $\begin{array}{l}\text { Aspect } \\
\text { ratio }\end{array}$ & $\begin{array}{l}\text { Angle } \\
(\mathrm{rad})\end{array}$ & $\begin{array}{l}\text { NN Dist } \\
(\mu \mathrm{m})\end{array}$ \\
\hline Mean & $\begin{array}{l}542 \\
(105)\end{array}$ & $\begin{array}{l}1.2 \\
(1.5)\end{array}$ & $\begin{array}{l}0.7 \\
(0.6)\end{array}$ & $\begin{array}{l}68 \\
(57)\end{array}$ \\
\hline $\begin{array}{l}\text { Standard } \\
\text { deviation }\end{array}$ & $\begin{array}{l}503 \\
(222)\end{array}$ & $\begin{array}{l}0.3 \\
(0.6)\end{array}$ & $\begin{array}{l}0.4 \\
(0.5)\end{array}$ & $\begin{array}{l}58 \\
(64)\end{array}$ \\
\hline Minimum & 3 & $\begin{array}{l}1.0 \\
(3)\end{array}$ & $\begin{array}{l}0 \\
(0)\end{array}$ & $\begin{array}{l}5 \\
(4)\end{array}$ \\
\hline Maximum & $\begin{array}{l}2242 \\
(1444)\end{array}$ & $\begin{array}{l}5.1 \\
(4.8)\end{array}$ & $\begin{array}{l}1.6 \\
(1.6)\end{array}$ & $\begin{array}{l}269 \\
(320)\end{array}$ \\
\hline Count & $\begin{array}{l}693 \\
(756)\end{array}$ & $\begin{array}{l}693 \\
(756)\end{array}$ & $\begin{array}{l}693 \\
(756)\end{array}$ & $\begin{array}{l}693 \\
(756)\end{array}$ \\
\hline
\end{tabular}

Despite the lower initiation porosity \% in Rene N5 it is clear that there are more, smaller pores. It should be noted that they also seem to have a higher aspect ratio. By taking porosity measurements from the fracture surface we are of course looking at a particular $2 \mathrm{D}$ slice through the microstructure, where the fatigue initiating porosity may be expected to have it's most critical dimensions (in terms of fatigue initiation). A number of values were then calculated for all the fatigue initiating porosity in each test specimen: aspect ratio (from both manual and TAP measurements), elliptical area based on major and minor axes, as well as the TAP measured actual pore area, depth below the notch root etc. A main initiating pore was identified where possible for each test where multiple initiation points were recorded. In the absence of an obvious main initiating pore, the largest initiating pore has been identified. The total area of initiating pores per test specimen has also been calculated as well as average values of all the measurements for the individual initiating pores. Scatter plots were systematically generated to examine the effect of each variable on cycles to failure for each initiating pore, average initiating pore values and main initiating pore values. The variable that showed the greatest correlation with cycles to failure was the sum area of initiating pores (as shown in Figure 8) with no clear correlation to any of the other individual measured parameters. Comparison of statistical pore data obtained from a polished section and those measurements taken for initiating pores on the fracture surface indicated that the cracks form on intersections with the greatest cross-sectional area (most critical stress concentration) as the initiating pore dimensions were significantly higher than the values derived from a random crosssection. It is noticeable that the Rene N5 samples tend to have the higher total area of initiating pores and the shorter lifetimes, corresponding to the multiple initiation sites which tended to be seen in this alloy.

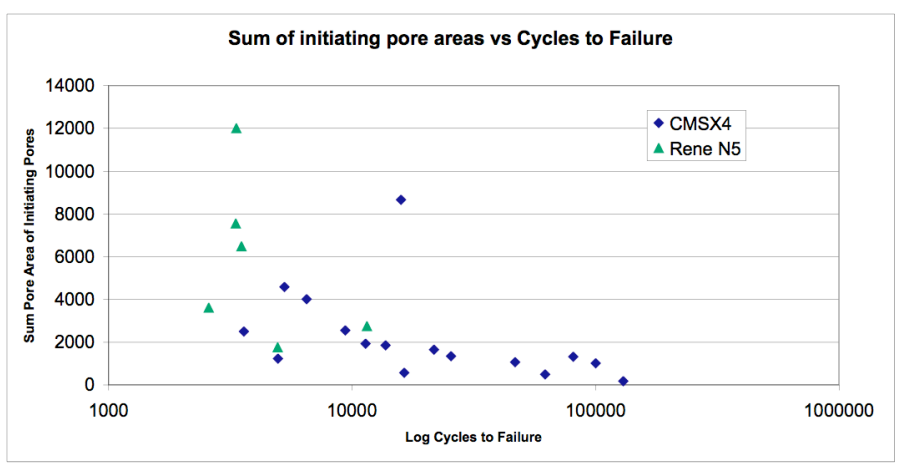

Figure 8 . Total area of initiating pores versus cycles to failure for notch fatigue tests at a $\Delta \varepsilon=1.38 \%$ in the notch root for CMSX4 and Rene N5

\section{Discussion}

Long crack growth rate data for CMSX4 single crystals has been presented elsewhere [8]. The improved long crack propagation fatigue resistance in orientation A compared to orientation B has been linked to differing orientations and amounts of interdendritic porosity (giving increased crack path roughness and shielding), increased stiffness along the crack growth direction (with implications for shear band decohesion) and lower resolved shear stresses along active slip systems, limiting faster Stage I crack growth. The faster crack growth rates which are generally seen in vacuum compared to air indicate the homogenising effect of oxidation on slip, suppressing faster Stage I crack growth and possibly increasing oxide induced closure. However the propagation data is for large through thickness defects, where shielding effects due to any faceted crack growth may play a role, the correlation with expected short fatigue crack growth rates for naturally initiating defects remains to be proven.

The change in fracture surface features observed in the notch fatigue tests with temperature and environment (with more faceted crack growth observed at lower temperatures in vacuum) are attributed to thermally activated cross-slip homogenising crack tip deformation processes as temperature increases [11]. As the vacuum environment produces more faceted crack growth than equivalent tests in air, this implies that oxygen affects slip reversibility within the crack tip process zone and/or embrittles the superalloy immediately ahead of the crack tip, affecting the crack propagation mode observed.

The halo observations around sub-surface initiating pores (Figure 6) are attributed to the point where the initial crack growth that has occurred in vacuum, breaks through to the top surface and is subsequently oxidised, producing a different fracture surface to subsequent oxidation assisted fatigue as the crack continues to propagate in air. These interdendritic pores, formed by shrinkage during casting, have highly complex 3D shapes and relatively high aspect ratios, so act as potent stress concentrators. The brittle, stiffer oxide in the notch root will continuously break off (due to strain mismatch between metal substrate and oxide during load cycling) resulting in a thick notch root oxide layer. A surface pore provides an additional stress concentration feature (and hence greater local plasticity in the metal substrate) so during the load cycle, stress transfer to the hard brittle oxide causes repeated cracking and re-oxidation within surface pores, building up an oxide plug. This may reduce the effective stress concentration of 
such surface pores by providing a compressive stress within or around the pore. Thus in the air tests, crack initiation moves to subsurface pores close to the notch root. Very similar subsurface initiation behaviour was seen in Rene $\mathrm{N} 5$ tested at $650^{\circ} \mathrm{C}$ in air, but in all cases multiple initiation sites were observed (Figure $5 \mathrm{~b}$ ) indicating a greater prevalence of porosity initiating fatigue, and this is reflected in the generally greater total initiating porosity area observed in these specimens (which was correlated with shorter lifetimes). In vacuum conditions in the CMSX4 tests, fatigue crack initiation from surface or close-to-surface pores was typically observed (Figure 7) and this would seem to back up the argument for how oxidation may be shifting the initiation process to sub-surface rather than surface porosity.

In considering the effects of individual initiating porosity measurements, the sum area of all initiating pores showed the greatest correlation to the fatigue life tests (conducted at the same notch root strain levels) as opposed to the main initiating pore area, or the aspect ratio of the initiating pore or depth below the surface.

The location of the critical initiation point will be due to a combination of the stochastics of pore position, size and shape combined with the stress state at the notch root (which can be seen in Figure 9 to be approximately constant, for the ranges of initiation site positions observed in this work).

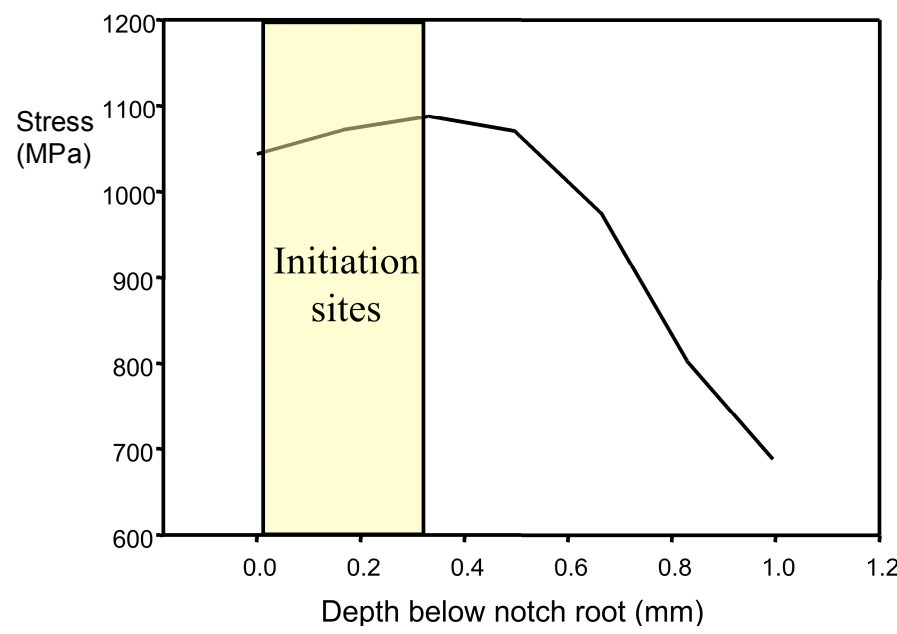

Figure 9. Predicted stress levels in MPa plotted against depth below the notch root based on elasto-plastic FE analysis of the Unotch specimen, compared to the typical positions of observed initiation sites.

Clearly the availability of a pore, and the stress concentration associated with its size and shape, and the amount of crack growth (due to its position) will affect the lifetime. It appears likely that the sum total of initiating porosity will account indirectly for coalescence events and therefore this is why it provides the best simple correlation with observed fatigue life, rather than any of the other individual porosity measurements. It is surprising that aspect ratio is not found to correlate with fatigue life, as this may be expected to be a good measure of the relative stress concentration associated with a pore shape, however it is likely that the simplified elliptical assumptions employed in trying to characterise these complex pore shapes has failed to capture the true stress concentration features of the actual pore shape. In terms of trying to combine the relevant porosity measurements to define fatigue life, the following crack growth model is therefore proposed:

A deterministic fracture mechanics based lifing model (discussed in more detail elsewhere) [12] has been developed to explain some of the observed lifetime scatter in terms of the size and location of the main crack initiating micro-pores, based on the following assumptions: (1) Micro-pores are ellipses, along $<100>$ directions (due to interdendritic nature of pores) (2) Subsurface crack growth is controlled by long fatigue crack propagation along $<100>$ directions (3) Growth of sub-surface cracks occurs in a constant stress field (all cracks initiated in the plastic yielding region close to the notch surface). (4) On breaking through to the specimen surface, the crack becomes a semi-circle with radius equivalent to the diameter of the internal crack just prior to breakthrough (5) Subsequent long crack growth occurs for the appropriate orientation until $K_{\max }=60 \mathrm{MPa} \sqrt{\mathrm{m}}$. A short computer code was written in $C++$ to perform the crack growth analysis. The schematic of the model process can be seen in Figure 10

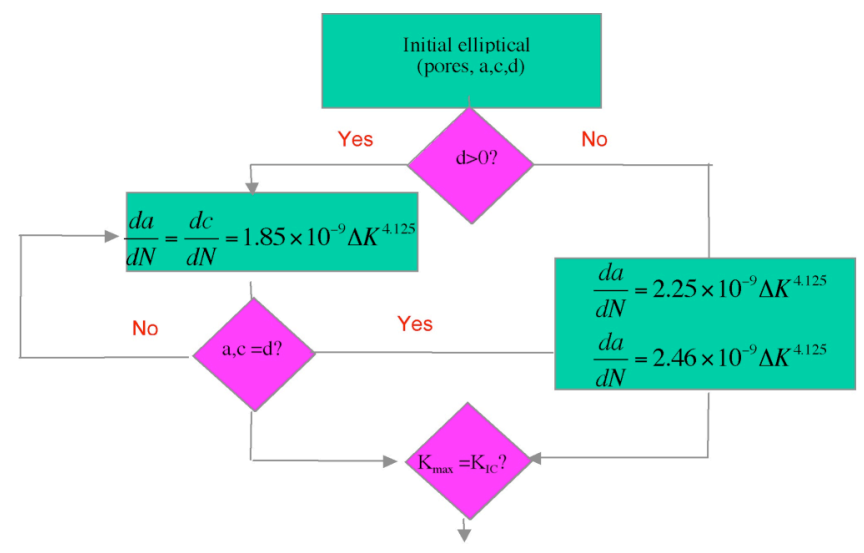

Figure 10. Schematic of deterministic fracture mechanics model, $a$ and $c$ are the major and minor axes of the elliptical approximation of the pore, $d$ is the distance below the notch root

The subsurface flaws modelled quickly adopt a circular morphology when assessing $\Delta \mathrm{K}$ levels around the ellipse and using orientation $\mathrm{B}$ vacuum long crack growth data for growth along the $<001>$ axes. This is consistent with the circular halo observations around these pores, where the previously sub-surface crack breaks through to the surface and the crack growth surface produced in vacuum is subsequently oxidised, resulting in a differing fracture surface appearance to subsequent oxidationfatigue crack growth. In addition a comparison of long crack fracture surfaces and the notch fatigue fracture surfaces has allowed for comparison of the relative $\Delta \mathrm{K}$ calibrations used for the short cracks in the model and for the experimentally derived fatigue crack growth laws for long cracks. This has shown reasonable correlation between the derived K-values and onset of extended Stage I crack growth at high $\Delta \mathrm{K}$ levels in both specimen geometries. This result implies that the notch stress field gradient in the $8 \mathrm{~mm} \times 8 \mathrm{~mm}$ bend bars has a limited effect at these crack sizes.

Before applying the model to actual experimental data a more stochastic interrogation of the model predictions via sensitivity studies of the effects of possible porosity distributions, scatter in crack growth laws and other materials varaiables was carried out. 
Minitab software has been used to perform a full factorial design of experiments (DOE) analysis using idealised pore geometry information. The test matrix uses three levels for pore geometry and depth, with a 2 level field for sample orientation. This produces 54 combinations of the varying inputs. The maximum, minimum and average values for pore dimensions and depth have been used. Interaction plots have been created for both the internal life (for sub-surface crack growth under vacuum) Figure 11 and the total life predicted by the model Figure 12 .

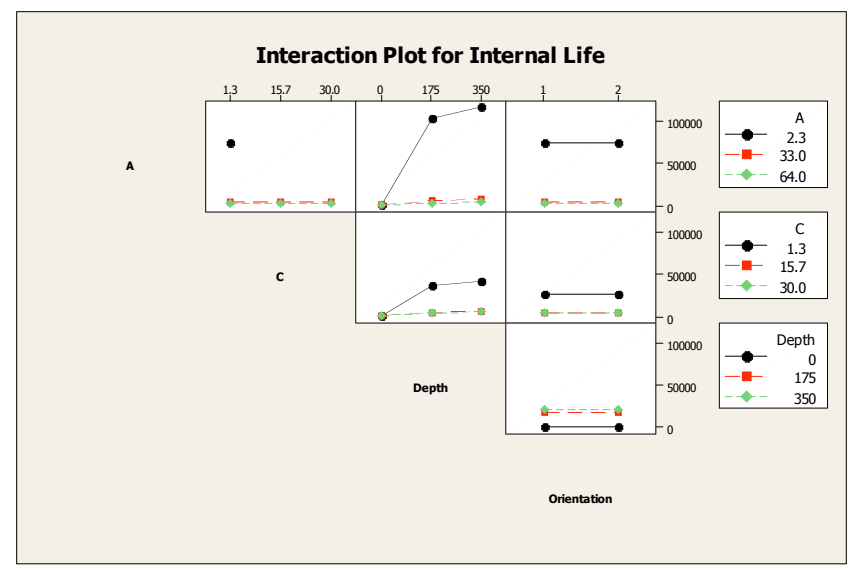

Figure 11. Interaction plot for $a, c$ and $d$ with respect to subsurface life

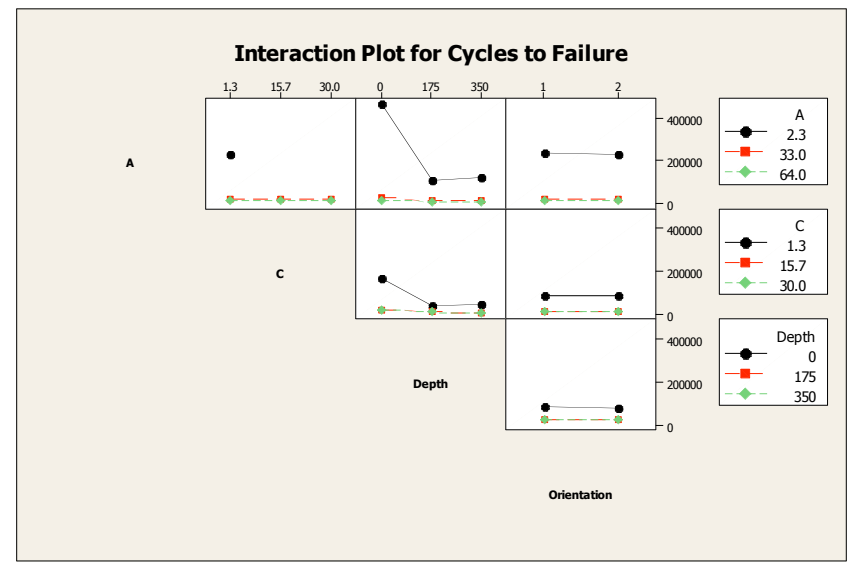

Figure 12. Interaction plot for $a, c$ and $d$ with respect to total life

Each shows the effect of two variables with respect to fatigue life (right hand axis). The scale for one variable is given along the top, with the second variable inferred through the legends (far right). Certain combinations where the major pore dimension $(a)$ is less than the minor one $(c)$ are not shown as $a>c$ by definition. The internal life model shows that the depth of the pore has most effect when $a$ or $c$ are small and $d$ is large, resulting in a longer lifetime. This combination gives rise to the longest crack growth distance required for the subsurface crack to reach the surface. The effect of aspect ratio is relatively small and orientation has no effect on internal life (as orientation B long crack propagation is always used). Interaction plots for total life however show that small pores near or at the surface give the longest lifetimes. It should be noted that the crack growth rates in vacuum for CMSX4 were faster in vacuum than in air, so it follows that a small initiation point from which the majority of crack growth will be in air will yield the longest overall lifetime. The major dimension, $a$, is seen to be the next most important factor in the model, but does not appear to be coupled with the $c$ dimension to the extent expected. A long thin pore does not seem to significantly shorten or increase fatigue life more than a long fat pore. It has been shown numerically that crack growth in a sub-surface ellipse occurs more quickly along the minor axis, which will experience a higher $\Delta K$ level, thus causing any ellipse to quickly assume a circular shape. Any coupling between variables is more likely to come from the relationship between area and lifetime rather than aspect ratio and lifetime.

The model sensitivity to the materials properties used $(C, m$ and $K_{\max }$ ) has been evaluated by considering a full factorial DOE for a 3 level experiment with 5 inputs (including 2 sets of differing $C$ and $m$ values to reflect the two sets of fatigue crack growth laws used in the model) and based on an average pore dimension and distance. This generated 243 results. The average effects of each input are shown in Figure13

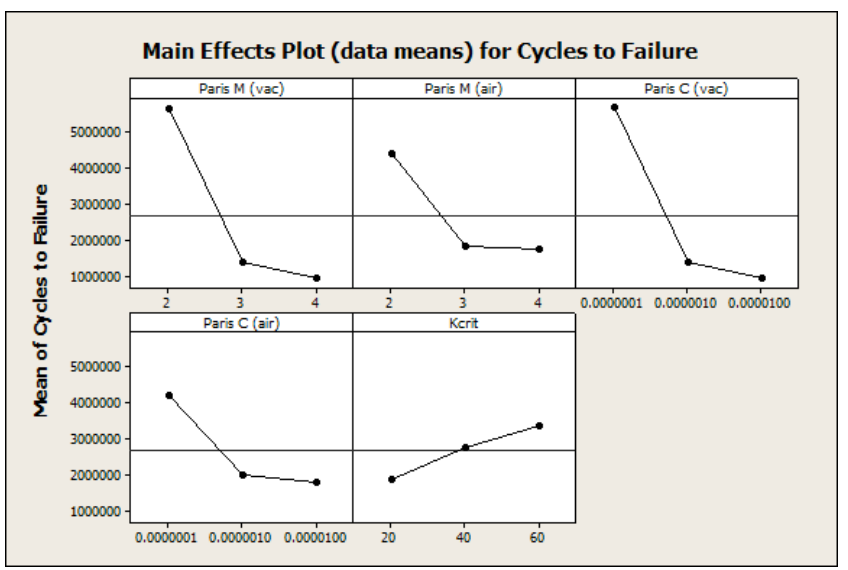

Figure 13. Average effects for change in material properties vs cycles to failure for an average sized pore

Sensitivity to the crack growth law constants, $C$ and $m$ is high. Low values of $C$ and $m$ tend to give longer lifetimes (as would be expected) with an apparent inverse power law relationship on total life. It is clearly therefore important that the crack growth data used is representative. The long crack data should be repeat tested for scatter assessment, and the effects of faceted crack growth on overall crack growth rates evaluated further, as the shielding from such features will not necessarily occur in short crack behaviour. Ideally short crack growth rates at temperature should be assessed, but the formation of significant oxide scale precluded this approach. At very long lives, changes in crack growth rate parameters in vacuum have a greater effect on total life. The effect of $K_{\max }$ on lifetime appears to be linear, with some evidence it levels off at higher $K$-levels, which can be linked to the fact that crack propagation rates at higher $K$-levels are so fast, that the increased contribution from further crack growth up to a higher allowable $K_{\max }$ becomes negligible in terms of overall lifetime.

The model has also been presented with data for all pores identified as initiation points from both alloys. Crack growth rates from CMSX4 have been used in the absence of appropriate fatigue crack growth data for the Rene N5. 
Table III. Lifetime data, $\Delta \varepsilon=1.38 \%$ compared with model predictions based on major initiation site distance from notch root as a function of temperature and orientation (where* indicates multiple initiation sites).

\begin{tabular}{|c|l|l|l|l|l|}
\hline Temp & Material & Env. (A/B) & Life & $\begin{array}{l}\text { Internal } \\
\text { predicted }\end{array}$ & $\begin{array}{l}\text { Total } \\
\text { predicted }\end{array}$ \\
\hline $650^{\circ} \mathrm{C}$ & CMSX4 & air (A) & 25500 & 4900 & 8000 \\
$650^{\circ} \mathrm{C}$ & CMSX4 & air (B) & $6500^{*}$ & 4000 & 10400 \\
$650^{\circ} \mathrm{C}$ & CMSX4 & vacuum (A) & $15871^{*}$ & 0 & 11500 \\
$650^{\circ} \mathrm{C}$ & CMSX4 & vacuum (B) & 9378 & 0 & 19400 \\
$725^{\circ} \mathrm{C}$ & CMSX4 & air (A) & $5271^{*}$ & 5300 & 9500 \\
$725^{\circ} \mathrm{C}$ & CMSX4 & air (B) & $13717^{*}$ & 8700 & 10900 \\
$725^{\circ} \mathrm{C}$ & CMSX4 & vacuum (A) & 11363 & 1100 & 20200 \\
$725^{\circ} \mathrm{C}$ & CMSX4 & vacuum (B) & 19841 & 1000 & 22800 \\
$650^{\circ} \mathrm{C}$ & Rene N5 & air (A) & $3346^{*}$ & 1800 & 15200 \\
$650^{\circ} \mathrm{C}$ & Rene N5 & air (A) & $11490^{*}$ & 4800 & 32800 \\
$650^{\circ} \mathrm{C}$ & Rene N5 & air (A) & $4945^{*}$ & 6100 & 25100 \\
$650^{\circ} \mathrm{C}$ & Rene N5 & air (B) & $3325^{*}$ & 2400 & 17000 \\
$650^{\circ} \mathrm{C}$ & Rene N5 & air (B) & $2573^{*}$ & 3500 & 18000 \\
$650^{\circ} \mathrm{C}$ & Rene N5 & air (B) & $3507^{*}$ & 0 & 20400 \\
\hline
\end{tabular}

The predicted lifetimes based on the main initiating pore (see Table III) provide partial explanation of the observed lifetime scatter, with reasonably good correlation for the CMSX4 data, where, with the exception of 2 tests, the model is conservative and under-predicting lifetimes. Reasons for this may include: (1) Instant initiation is assumed from the critical pore, this may not be true in all cases, number of cycles to initiation could be treated as a probabilistic function if the model were to be developed further. (2) The model does not take account of short crack growth behaviour (long crack growth data has been used) and typically short cracks have higher crack growth laws than similar long crack data although they may also show more retardation. The Rene N5 lifetimes are however consistently over-predicted. This could reflect the use of inappropriate crack growth laws (CMSX4 data was used) or the effects of crack coalescence, as this alloy showed the greatest number of initiating pores on the fracture surface. Multiple initiations and coalescence will yield shorter lives than those predicted from crack growth from a single pore in the model. Modifications are therefore required to allow for multiple initiation points in the model, and their coalescence behaviour. The effect of multiple cracks on each other's stress fields is also likely to be complex and will require changes to the underlying fracture mechanics assumptions of the model.

\section{Summary and Conclusions}

Crack initiation in these two alloys was dominated by interdendritic $\langle 100\rangle$ aligned micro-porosity, which is directly affected by the secondary orientation of the sample, although no clear effect of secondary orientation on overall notch fatigue life has been found. CMSX4 showed better notch fatigue resistance than Rene N5. Surface oxide cracks did not appear to initiate critical fatigue cracks. At high temperature in vacuum, initiation occurs from pores at or close to the notch surface, whereas at high temperatures in air, initiation occurs almost exclusively at subsurface pores, indicating a possible in-filling of surface pores by oxidation. Scatter in lifetimes at the same applied notch root strain level can be partially modelled by a multi-part Paris type lifing approach, modelling initial sub-surface crack growth from a pore under vacuum conditions and subsequent crack growth in air once the crack breaks through to the surface. Vacuum long crack propagation rates at $650^{\circ} \mathrm{C}$ indicate that apparent vacuum lifetime improvement is not necessarily due to slower propagation. Development of the model requires more realistic crack growth laws, modifications allowing for crack coalescence events and to be tested more extensively against increased amounts of experimental data.

\section{References}

[1] P.A.S. Reed, X.D. Wu and I. Sinclair, Met. \& Mater. Trans, 2000, 31A, 109-123

[2] K. Harris, G.L. Erickson, S.L. Sikkenga, W.D. Brentnall, J.M. Aurrecoechea and K.G. Kubarych, $7^{\text {th }}$ International symposium on superalloys, Seven Springs, USA, 1992, TMS (The Minerals, Metals and Materials Society) Superalloys 1992, 1992, 297

[3] P.J. Warren, A. Cerezo and G.D.W. Smith, Mater. Sci. Eng. A, 1998, 250(1), 88-92

[4] D. W. MacLachlan and D. M. Knowles, Fatigue and Fracture of Engineering Materials and Structures, 2001, 24 (8), 503-521

[5] J. Tong, S. Dalby, J. Byrne, M.B. Henderson and M.C. Hardy, International Journal of Fatigue, 2001, 23 (10), 897-902

[6] F. Schubert, T. Rieck and P.J. Ennis, $9^{\text {th }}$ International symposium on superalloys, Seven Springs, USA, 2000, ed. T.M. Pollock, R.D.Kissinger, R.R. Bowman, K.A. Green, M. McLean, S. Olson and J.J. Scirra, TMS (The Minerals, Metals and Materials Society) Superalloys 2000, 2000, 341

[7] S.A. Padula, A. Shyam, D.L. Davidson, W.W. Milligan, Editor(s): Chan KS, Liaw PK, Bellows RS, Zogas T, Soboyejo WO, David L Davidson Symposium on High Cycle Fatigue, TMS Annual Meeting, Seattle, Washington, 2002, Minerals, Met \& Mat Soc, 2002, 183-189

[8] M.R. Joyce, X. Wu and P.A.S. Reed, Mater Lett, 2004, 58 (12), 99-103

[9] M.D. Miller, University of Southampton EngD Thesis. (2007)

[10] J. Boselli, P. D. Pitcher, P. J. Gregson, I. Sinclair, Journal of Microscopy, 1999, 195, 104-112.

[11] J.E. King, Mat. Sci Tech, 1987, 3 (9), 750-764

[12] M.D. Miller, P.A.S. Reed, M.R. Joyce, M.B. Henderson, J.W. Brooks, I. Wilcock and X. Wu, Mater Sci Tech, 2007, 23(12) 1439-1445 